OPEN ACCESS

Edited and reviewed by: Mark A. Elgar

The University of Melbourne, Australia

*Correspondence:

Rodney L. Honeycutt rodney.honeycutt@pepperdine.edu

Specialty section:

This article was submitted to Phylogenetics, Phylogenomics, and Systematics,

a section of the journal

Frontiers in Ecology and Evolution

Received: 01 June 2021

Accepted: 11 June 2021

Published: 02 July 2021

Citation:

Honeycutt RL (2021) Editorial: DNA

Barcodes: Controversies,

Mechanisms, and Future Applications.

Front. Ecol. Evol. 9:718865

doi: 10.3389/fevo.2021.718865

\section{Editorial: DNA Barcodes: Controversies, Mechanisms, and Future Applications}

\author{
Rodney L. Honeycutt* \\ Natural Science Division, Pepperdine University, Malibu, CA, United States
}

Keywords: DNA barcodes, metabarcoding, taxonomy, biosecurity and regulation, microbial diversity, selection, mtDNA

\section{Editorial on the Research Topic}

\section{DNA Barcodes: Controversies, Mechanisms, and Future Applications}

Biodiversity provides ecosystem services and direct and indirect benefits to society. Unfortunately, human activities are now accelerating the extinction rate of biodiversity at an alarming rate, and in many cases, species will disappear before their discovery. Except for vertebrates and plants, knowledge about the number of species for many groups of organisms and the biogeographic regions harboring high levels of biodiversity is lacking (Honeycutt et al., 2010). Traditional taxonomy alone cannot achieve an all-species inventory, but the integration of conventional taxonomy, DNA-based technology, and bioinformatics increases the feasibility of filling in the knowledge gaps.

In 2003, Hebert et al. (2003a,b) proposed using an $\sim 650$ bp sequence from the mitochondrial cytochrome c oxidase subunit I gene (COI) as a valuable barcode for identifying species in the kingdom Animalia. Given the rate of change and selection patterns, mitochondrial genes like COI demonstrate patterns of change conducive to their use as DNA barcodes (Shtolz and Mishmar). BOLD (Barcode of Life Data System) is a web-based reference system of COI sequences developed to allow species-level identification (Ratnasingham and Hebert, 2007). BOLD is now international and is cataloging sequences of species at a rapid rate.

What are some trends in the use of DNA barcodes? DeSalle and Goldstein present a summary of DNA barcoding papers published over the last 15 years. Throughout this period, the primary focus has been alpha taxonomy (the identification and delimitation of species) and the discovery of cryptic species not easily diagnosed by morphology. A parallel survey by Yang et al. indicates that in China, the primary use of species identification emphasized food safety, control of pests and invasive species, and traditional medicine. More recently, researchers in China are also using barcodes to discover cryptic species and create biodiversity inventories. Given continued global threats to biodiversity, species discovery is likely to remain a primary use for barcodes.

The concept of DNA barcoding has revolutionized fields of science interested in inventorying biodiversity (Jansen and Hallwachs, 2016), ecological studies of species interactions and community structure (Valentini et al., 2008; Joly et al., 2013), conservation biology (Shapcott et al., 2015), assessment of biosecurity risks from invasive species (Molnar et al., 2008; Madden et al., 2019), and forensics (Mwale et al., 2017).

Several papers in this series highlight the use of barcodes related to food safety and biosecurity in marine ecosystems. Silva et al. examined the accuracy of mini-barcodes to identify mixed species of fish included in processed fish balls and cakes. One finding was that not all species are equally identifiable. As a result, these authors recommend cloning of PCR products and 
next-generation sequencing. Suarez-Menendez et al. describe the use of eDNA (environmental DNA), extracted from $6 \mathrm{~L}$ of water, Illumina sequencing, and metabarcoding to identify invasive species and indicators of loss of environmental quality in coastal lagoons of the Mediterranean. This approach proved helpful in identifying habitats threatened by loss of environmental quality. Finally, Garcia-Vazquez et al. used a barcode approach for establishing biotic surveys of ports vulnerable to the importation of invasive or alien species. These ports showed differences in their susceptibility to infiltration of non-native species, and the authors offer several explanations for these differences.

Technological advances allow for faster acquisition of sequences at less cost (Hebert et al., 2018; Knot et al., 2020). Multiplex sequencing with Illumina MiSeq platform is a good example of such advancements. Using dried museum specimens of saproxylic beetles and DNA barcodes, Sire et al. compare the effectiveness of both Illumina sequencing and traditional Sanger sequencing. Recovery of barcode sequences was similar for the two methods, with the cost per sequence considerably less for the Illumina method. The paper by Porter and Hajibabaei published in this series provides an overview of current methods and implications for species identification in challenging groups. They present a review of the application of metabarcoding for sampling whole communities. Additionally, they discuss the bioinformatic approach needed to process metabarcode data.

COI is not the only useful barcode marker. Chloroplast and nuclear genes represent barcode markers for plant species identification (Kress, 2017), ribosomal ITS for fungi (Lücking et al., 2020), 18S rDNA, 28S rDNA, and ITS for protists (Pawlowski et al., 2012), and 16S rDNA for bacteria and archaebacteria (Lebonah et al., 2014). In each of these cases, databases exist, which is a requisite for any barcode marker. In this series, Pierce discusses the limitations of using only COI and argues for the inclusion of ultraconserved elements (UCEs) from the nuclear genome, which he suggests would strengthen species identification across divergent groups of taxa. Unfortunately, one constraint of UCEs is the lack of an adequate database.

Is DNA barcoding a challenge to systematic biology? Taxonomy is a component of systematics that emphasizes identification, delimitation, and description of species. The importance of taxonomy is evident from the specimens collected over the centuries and housed in natural history museums. These specimens serve as a valuable resource for those employing DNA barcode technology for species identification and the establishment of databases. Therefore, natural history museums and expert taxonomists are essential for cataloging biodiversity (Pinheiro et al., 2019). Cognato et al.'s research

\section{REFERENCES}

Hebert, P. D. N., Braukmann, T. W. A., Prosser, S. W. J., Ratnasingham, S., deWaard, J. R., Ivanova, N. V., et al. (2018). A sequel to sanger: amplicon sequencing that scales. BMC Genomics 19:219. doi: 10.1186/s12864-018-4611-3

Hebert, P. D. N., Cywinska, A., Ball, S. L., and deWaard, J. R. (2003a). Biological identifications through DNA barcodes. Proc. R. Soc. Lond. B 270, 313-321. doi: $10.1098 / \mathrm{rspb} .2002 .2218$ on ambrosia beetles demonstrates that DNA barcodes cannot replace taxonomic expertise. For some species of beetles, the authors did not observe a barcode gap, and confidence in species identification decreased with an increase in percent divergence. Phylogenetics represents another component of systematics used to determine relationships among organisms. The resultant phylogeny is useful for comparative studies and the derivation of classifications. As noted by DeSalle and Goldstein, single DNA barcode markers and the distance-based approach for identifying species are insufficient for diagnosing phylogenetic relationships. Researchers now use sequences from multiple genes and genomes to examine evolutionary divergence within and between species. An excellent example in this series is the study by Mankga et al., who used both plant barcode and nuclear gene sequences to study diversification and phylogenetic relationships of cycads.

As Thaler notes, our current knowledge of microbial biodiversity is unknown and difficult to discern with approaches used for multicellular organisms. As a result, early efforts at understanding microbial diversity emphasized the use of molecular markers (Pace, 1997). Today, more advanced methods are beginning to estimate the number of eubacteria and archaebacteria species (Louca et al., 2019). Other problems with microbial diversity noted by Thaler are the generation time or rate at which microbes (single-celled organisms and viruses) evolve, the difficulty in identifying OTUs (operational taxonomic units), and the exchange of genes between microbes via horizontal gene transfer. All these factors complicate our ability to evaluate microbial diversity in space and time.

The breadth of papers presented in this series and the plethora of DNA barcode papers published each year indicate that barcoding will continue to be an important tool for realizing an all species inventory. Advancements in genomics and bioinformatics continue to be developed, and these advancements offer accessibility of these tools to a broad range of researchers interested in the application of barcodes.

\section{AUTHOR CONTRIBUTIONS}

The author confirms being the sole contributor of this work and has approved it for publication.

\section{ACKNOWLEDGMENTS}

The author would like to acknowledge David Thaler for his contributions as topic editor to this Research Topic. I wish to thank the authors and reviewers who participated in this series on DNA barcodes. 
Cambridge University Press), 1-35. doi: 10.1017/CBO978051177759 2.002

Jansen, D. H., and Hallwachs, W. (2016). DNA barcoding the Lepidoptera inventory of a large complex tropical conserved wildland, Area de Conservacion Guanacaste, northwestern Costa Rica. Genome 59, 641-660. doi: 10.1139/gen-2016-0005

Joly, S., Davies, T. J., Archambault, A., Bruneau, A., Derry, A., Kembel, S. W., et al. (2013). Ecology in the age of DNA barcoding: the resource, the promise and the challenges ahead. Mol. Ecol. Resour. 14, 221-232. doi: 10.1111/1755-0998. 12173

Knot, I. E., Zouganelis, G. D., Weedall, G. D., Wich, S. A., and Rae, R. (2020). DNA barcoding of nematodes using MinION. Front. Ecol. Evol. 8:100. doi: $10.3389 /$ fevo.2020.00100

Kress, W. J. (2017). Plant DNA barcodes: applications today and in the future. J. Sys. Evol. 55, 291-307. doi: 10.1111/jse.12254

Lebonah, D. E., Dileep, A., Chandrasekhar, K., Sreevani, S., Sreedevi, B., and, J. P., et al. (2014). DNA barcoding on bacteria: a review. Adv. Biol. 2014:541787. doi: $10.1155 / 2014 / 541787$

Louca, S., Mazel, F., Doebeli, M., and Parfrey, L. W. (2019). A census-based estimate of Earth's bacterial and archaeal diversity. PLoS Biol. 17:e3000106. doi: 10.1371/journal.pbio.3000106

Lücking, R., Aime, M. C., Robbertse, B., Miller, A. N., Ariyawansa, H. A., Aoki, T., et al. (2020). Unambiguous identification of fungi: where do we stand and how accurate and precise is fungal DNA barcoding? IMA Fungus 11:14. doi: 10.1186/s43008-02000033-z

Madden, M. J. L., Young, R. G., Brown, J. W., Miller, S. E., Frewin, A. J., and Hanner, R. H. (2019). Using DNA barcoding to improve invasive pest identification at U.S. ports-of-entry. PLOS ONE 14:e0222291. doi: 10.1371/journal.pone.0222291

Molnar, J. L., Gamboa, R. L., Revenga, C., and Spalding, M. D. (2008). Assessing the global threat of invasive species to marine biodiversity. Front. Ecol. Environ. 6, 485-492. doi: 10.1890/070064
Mwale, M., Dalton, D. L., Jansen, R., De Bruyn, M., Pietersen, D., Mokgokong, P. S., et al. (2017). Forensic application of DNA barcoding for identification of illegally traded African pangolin scales. Genome 60, 272-284. doi: 10.1139/gen-2016-0144

Pace, N. R. (1997). A molecular view of microbial diversity and the biosphere Science 276, 734-740. doi: 10.1126/science.276.5313.734

Pawlowski, J., Audic, S., Adl, S., Bass, D., Belbahri, L., Berney, C., et al. (2012). CBOL protist working group: barcoding eukaryotic richness beyond the animal, plant, and fungal kingdoms. PLoS Biol. 10:e1001419. doi: 10.1371/journal.pbio.1001419

Pinheiro, H. T., Moreau, C. S., Daly, M., and Rocha, L. A. (2019). Will DNA barcoding meet taxonomic needs? Science 365, 873-874 doi: $10.1126 /$ science.aay7174

Ratnasingham, S., and Hebert, P. D. (2007). BOLD: the barcode of life data system (http://www.barcodinglife.org/) Ecol. Notes 7, 355-364. doi: 10.1111/j.1471-8286.2007.01678.x

Shapcott, A., Forster, P. I., Guymer, G. P., McDonald, W. J. F., Faith, D. P., et al. (2015). Mapping biodiversity and setting conservation priorities for SE Queensland's rainforests using DNA barcoding. PLoS ONE 10:e0122164. doi: 10.1371/journal.pone.0122164

Valentini, A., Pompanon, F., and Taberlet, P. (2008). DNA barcoding for ecologists. Trends Ecol. Evol. 24, 110-117. doi: 10.1016/j.tree.2008.09.011

Conflict of Interest: The author declares that the research was conducted in the absence of any commercial or financial relationships that could be construed as a potential conflict of interest.

Copyright $\odot 2021$ Honeycutt. This is an open-access article distributed under the terms of the Creative Commons Attribution License (CC BY). The use, distribution or reproduction in other forums is permitted, provided the original author(s) and the copyright owner(s) are credited and that the original publication in this journal is cited, in accordance with accepted academic practice. No use, distribution or reproduction is permitted which does not comply with these terms. 